\title{
Rice Milling
}

\author{
Poonam Dhankhar \\ M.Tech (Food tech), G.J.U.S \& T, Hissar,
}

\begin{abstract}
The Rice milling is the process that helps in removal of hulls and bran's from paddy grains to produce polished rice. Rice is rich in genetic diversity with thousands of varieties grown throughout the world. Rice has been one of man's most important foods. Today, this unique grain helps sustain two-thirds of the world's population. It is life for thousands of millions of people. It is deeply embedded in the cultural heritage of their societies. About four-fifths of the world's rice are produced by small-scale farmers and are consumed locally.Milling is the process wherein the rice grain is transformed into a form suitable for human consumption, therefore, has to be done with utmost care to prevent breakage of the kernel and improve the recovery.the present paper lucidly explains ricce milling process and its importance
\end{abstract}

\section{INTRODUCTION}

Paddy or rice grain consists of husk and brown rice. Brown rice, in turn, contains bran which comprises the outer layer and the edible portion. Rice milling is removal or separation of husk (dehusking) and bran to obtain the edible portion for consumption. The process has to be accomplished with care to prevent excessive breakage of the kernel and improve recovery of paddy or rice. The extent of recovery during milling depends on many factors like variety of paddy, degree of milling required, the quality of equipments used, the operators, etc.

Milling is the process wherein the rice grain is transformed into a form suitable for human consumption, therefore, has to be done with utmost care to prevent breakage of the kernel and improve the recovery.Brown rice is milled further to create a more visually appealing white rice.After harvesting and drying, the paddy is subjected to the primary milling operation which includes de-husking as well as the removal of bran layers (polishing) before it is consumed. In this process the rice which is obtained after milling is called raw rice.An other process through which rice is obtained after milling is called "Parboiling Rice." Nearly $60 \%$ of the total rice produced in India is subjected to parboiling. Rice milling losses may be qualitative or quantitative in nature. Quantitative or physical losses are manifested by low milling recovery while low head rice recovery or high percentage of broken kernel reflects the qualitative loss in rice grains.

\section{METHOD OF MILLLING}

2.1) Traditional Method:Before the advent of mechanical milling, hand-pounding traditional method of rice milling was in practice. In fact, hand-pounding rice has got more nutritive value as compared to machine milling rice. In hand-pounding, a variety of implements is used such as :Mortor and Pestle, Hand Stone (Chakki)etc

2.2) Mechanical Method:With the introduction of mechanized mills, hand-pounding method has steadily decreased because it could not compete with machine mills. The conventional mills in use can be categorized into three main types :

- Huller mills

- Sheller-Huller mills

- Sheller-Cone Polisher mills.

\section{IMPORTANCE OF MILLING}

Milling is a crucial step in post-production of rice. The basic objective of a rice milling system is to remove the husk and the bran layers, and produce an edible, white rice kernel that is sufficiently milled and free of impurities. Depending on the requirements of the customer, the rice should have a minimum of broken kernels.

IV. THE RICE KERNEL COMPOSITION

Most rice varieties are composed of roughly $20 \%$ rice hull or husk, $11 \%$ bran layers, and $69 \%$ starchy endosperm, also referred to as the total milled rice. Total milled rice contains whole grains or head rice, and brokens. The by-products in rice milling are rice hull, rice germ and bran layers, and fine brokens.

V. MILLING SYSTEMS

A rice milling system can be a simple one or two step process, or a multi stage process. In a one step milling process, husk and bran removal are done in one pass and milled or white rice is produced directly out of paddy. In a two step process, removing husk and removing bran are done separately, and brown rice is 
produced as an intermediate product. In multistage milling, rice will undergo a number of different processing steps. Depending on whether the the paddy is milled in the village for local consumption or for the marketing rice milling systems can be classified into the categories village rice mills and commercial mills.

\section{COMMERCIAL MILLING}

Commercial milling systems mill the paddy in stages, and hence are called multi-stage or multi-pass rice mills. The objective of commercial rice milling is to reduce mechanical stresses and heat buildup in the grain, thereby minimizing grain breakage and producing uniformly polished grain. Compared to village-level systems, the commercial milling system is a more sophisticated system configured to maximize the process of producing well-milled, whole grains.

The rice milling facility comes in various configurations, and the milling components vary in design and performance. "Configuration" refers to how the components are sequenced. The flow diagram below shows a modern commercial mill catering to the higher end market. It has three basic stages,

- the husking stage,

- the whitening-polishing stage, and

- the grading, blending, and packaging stage.

In modern rice mills, many adjustments (e.g. rubber roll clearance, separator bed inclination, feed rates) are automated for maximum efficiency and ease of operation. The whitener-polishers are provided with gauges that sense the current load on the motor drives which gives an indication of the operating pressure on the grain. This provides a more objective means of setting milling pressures on the grain.

\section{1) Objective of commercial milling:-}

A commercial rice miller will have following objectives:

- $\quad$ produce edible rice that appeals to the customer- i.e. rice that is sufficiently milled and free of husks, stones, and other non-grain materials

- maximize the total milled rice recovery out of paddy minimize grain breakage

\section{TERMINOLOGY}

To understand the different objectives of rice milling, please review the following terminology.

7.1) Rough rice: Also called paddy rice. Rice as it comes from the field. Rice kernels are still encased in their inedible, protective hull.

7.2) Brown rice, husked rice or cargo rice: The least processed form of rice. It has the outer hull removed, but still retains the bran layers that give it a characteristic tan color and nut-like flavor. Brown rice is edible but chewier texture than white rice. Cooking time of brown rice is longer than milled rice

7.3) Milled rice: Also called white rice, or rice after milling which includes removing all or part of the bran and germ from the rough rice.

7.4) Milling recovery: Total milled riceobtained out of paddy; expressed as weight percentage of milled rice (including brokens) obtained from a sample of paddy. The maximum milling recovery is $69-70 \%$ depending on rice variety, but because of grain imperfections and the presence of unfilled grains, commercial millers are happy when they achieve $65 \%$ milling recovery. Some village type rice mills have $55 \%$ or lower milling recovery.

7.5) Milling degree: A measure of the amount of bran removed from the brown rice

7.6) Head rice: Milled rice with length greater or equal to three quarters of the average length of the whole kernel. It is often expressed on a \% paddy or rough rice basis (on 14\% Moisture content basis).

7.7) Head rice recovery: Weight percentage of head rice (excluding brokens) obtained from a sample of paddy. Under controlled conditions head rice recovery can be as high as $84 \%$ of the total milled rice or $58 \%$ of the paddy weight. Commercial rice mills turn out $55 \%$ head rice on average, whereas head rice recovery of village type rice mills is in the order of $30 \%$.

7.8) Whole kernel: A milled rice grain without any broken parts

7.9)Broken kernel: Also called brokens. Depending on the rice mill this can be only one fraction or it can contain several fractions of different size:

- $\quad$ Large broken kernel: $50-75 \%$ of the whole kernel size

- Medium broken kernel: $25-50 \%$ of the whole kernel size

- Small broken kernel: less than $25 \%$ of the kernel size, can not pass through a sieve with $1.4 \mathrm{~mm}$ diameter holes

- Chips: fragments of a kernel which pass through a sieve with $1.4 \mathrm{~mm}$ diameter holes 
7.10) Impurities: Materials in the rice that are not part of the milled rice kernel. May include stones, husk, chaff, weed seeds, etc.

\section{VIII.}

THE MODERN RICE PROCESSMILLING

Modern rice milling processes consist of:

\begin{tabular}{|l|l|}
\hline Function & Stage \\
\hline removing all impurities and unfilled grains from the paddy & Pre-cleaning \\
\hline removing the husk from the paddy & Husking \\
\hline separating the husk from the brown rice/unhusked paddy & Husk aspiration \\
\hline separating the unhusked paddy from the brown rice & Paddy separation \\
\hline separating small stones from the brown rice & De-stoning \\
\hline removing all or part of the branlayer and germ from the brown rice & Whitening \\
\hline $\begin{array}{l}\text { improving the appearance of milled rice by removing remaining ran particles and by } \\
\text { polishing the exterior of the milled kernel }\end{array}$ & Soling \\
\hline separating small impurities or chips from the milled rice & Sifting \\
\hline separating small and large brokens from the head rice & Blending \\
\hline mix head rice with predetermined amount of brokens, as required by the customer \\
\hline preparing milled rice for transport to the customer & $\begin{array}{l}\text { Weighing and } \\
\text { bagging }\end{array}$ \\
\hline
\end{tabular}

Flow diagram of a modern rice mill

The flow diagram below represents the configuration and flow in a typical modern rice mill.

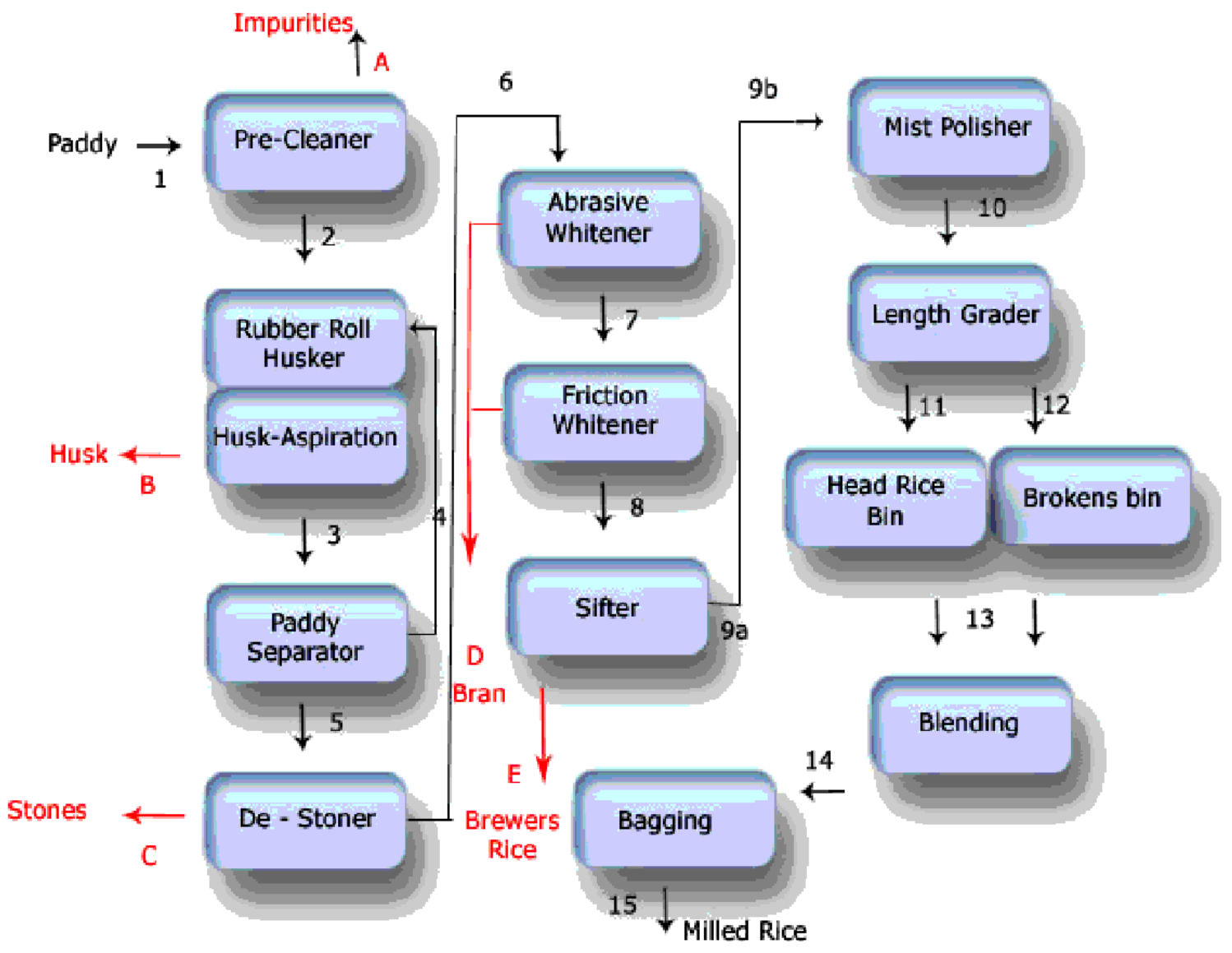

1 - paddy is dumped in the intake pit feeding the pre-cleaner

2 - pre-cleaned paddy moves to the rubber roll husker:

3 - mixture of brown rice and unhusked paddy moves to the separator

4 - unhusked paddy is separated and returned to the rubber roll husker

5 - brown rice moves to the destoner

6 - de-stoned, brown rice moves to the 1st stage (abrasive) whitener

7 - partially milled rice moves to the 2 nd stage (friction) whitener 
8 - milled rice moves to the sifter

9a - (for simple rice mill) ungraded, milled rice moves to bagging station

$9 \mathrm{~b}$ - (for more sophisticated mill) milled rice moves to the polisher1

10 - Polished rice, will move to length grader

11 - Head rice moves to head rice bin

12 - Brokens moves to brokens bin

13 - Pre-selected amount of head rice and brokens move to blending station

14 - Custom-made blend of head rice and brokens moves to bagging station

15 - Bagged Rice moves to the market

A - straw, chaff and empty grains are removed

B - husk removed by the aspirator

C - small stones, mudd balls etc. removed by de-stoner

D - Coarse (from 1st whitener) and fine (from 2 nd whitener) bran removed from the rice grainduring the whitening process

E - Small brokens/brewer's rice removed by the sifter

\section{IMPORTANT STEPS IN DETAIL}

9.1) Cleaning of paddy:-

Why cleaning the paddy?

Although harvested paddy grain may have gone through a cleaner before drying, wet paddy is difficult to clean thoroughly. Cleaning paddy prior to husking and whitening is crucial in attaining high milling recoveries.

Function of a pre-cleaner

A simple pre-cleaner used in rice mills usually contain an oscillating double screen bed with an aspirator. The first screen is a scalper that lets through the grain but retains straw. The second screen retains the grains but lets through broken grains and small stones or weed seeds. The air aspirator sucks out dust and the light empty grains. Air dampers are provided and have to be adjusted to prevent the good grain from being sucked out.

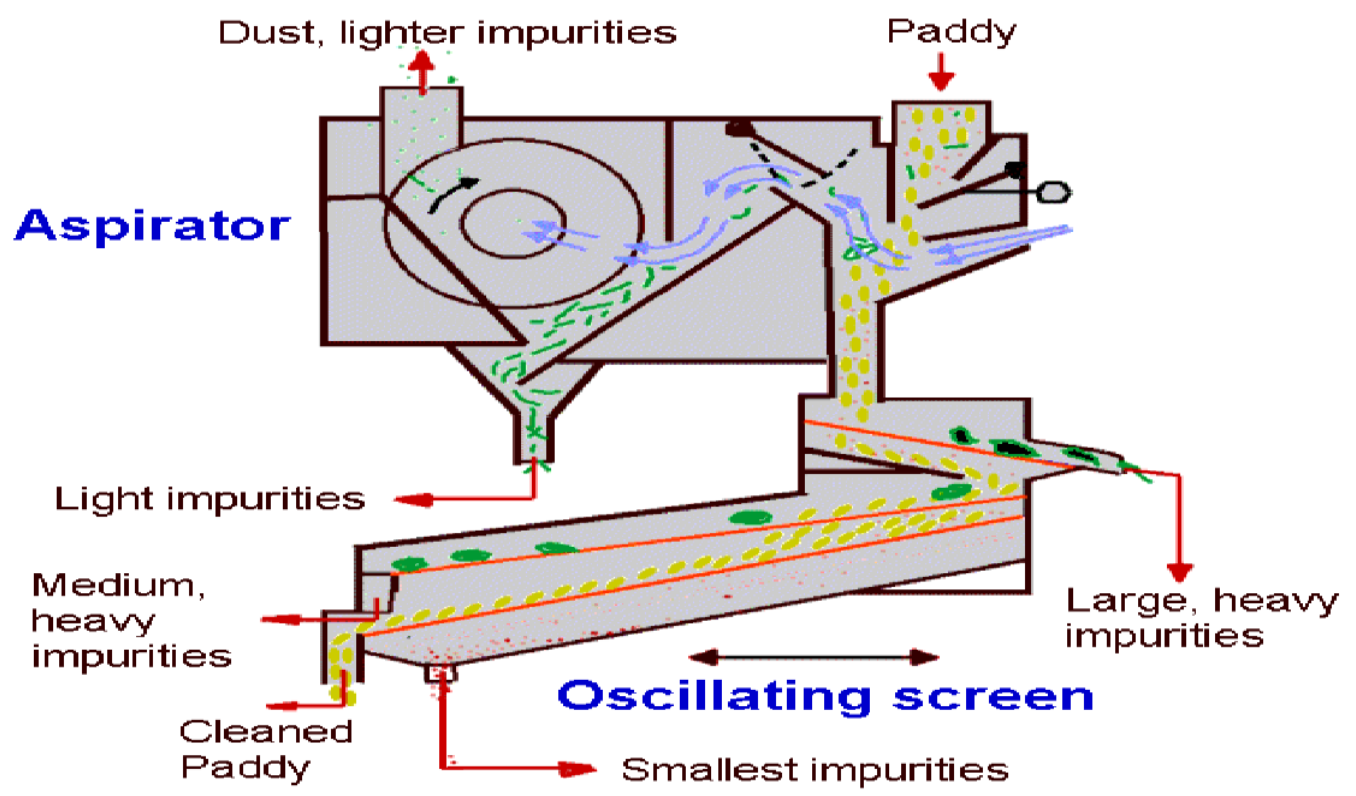

9.2) Husking:- ${ }^{[15]}$

What is husking?

Husking or de-hulling is a process for removing the rice hull from the rough rice.

Common husking technologies

Three different husking technologies are commonly used: Steel husker, underrunner disk husker and rubber roller husker. In order to separate the remaining unhusked paddy grains from from the brown rice fraction and feed them back into the husker a paddy separator is used.

Husking efficiency

The performance of a husker can be expressed by the husking efficiency, which is the $\%$ of husked rice in total grain flow. In a properly adjusted rubber roll husker, husking efficiencies can be as high as 95\%, however efficiencies are often lower. Besides machine adjustments, uniformity of grain thickness will affect the husking 
efficiency. If a mixture of varieties is fed into the husker, or paddy grain that did not mature uniformly in the field, husking efficiencies will be lower.

\section{Steel husker ${ }^{[6]}$}

The steel husker is in fact more than a husker since it also does the polishing. It is an adaptation of the "Engleberg" coffee huller, modified for milling rice. In earlier days this type of rice mill was very popular in most rice-growing countries. The "iron hullers", or "single pass mills" which all refer to the same mill are notorious for breaking the paddy grain. The fine brokens are mixed with the bran and the ground rice hull.

The steel husker removes the husks and whitens the rice in one pass. Paddy rice is fed into the machine and passes between a revolving steel shaft and a cylindrical shaped mesh screen. These machines are normally powered by a 5 to $20 \mathrm{hp}$ engine and are very simple to operate. They are relatively cheap.

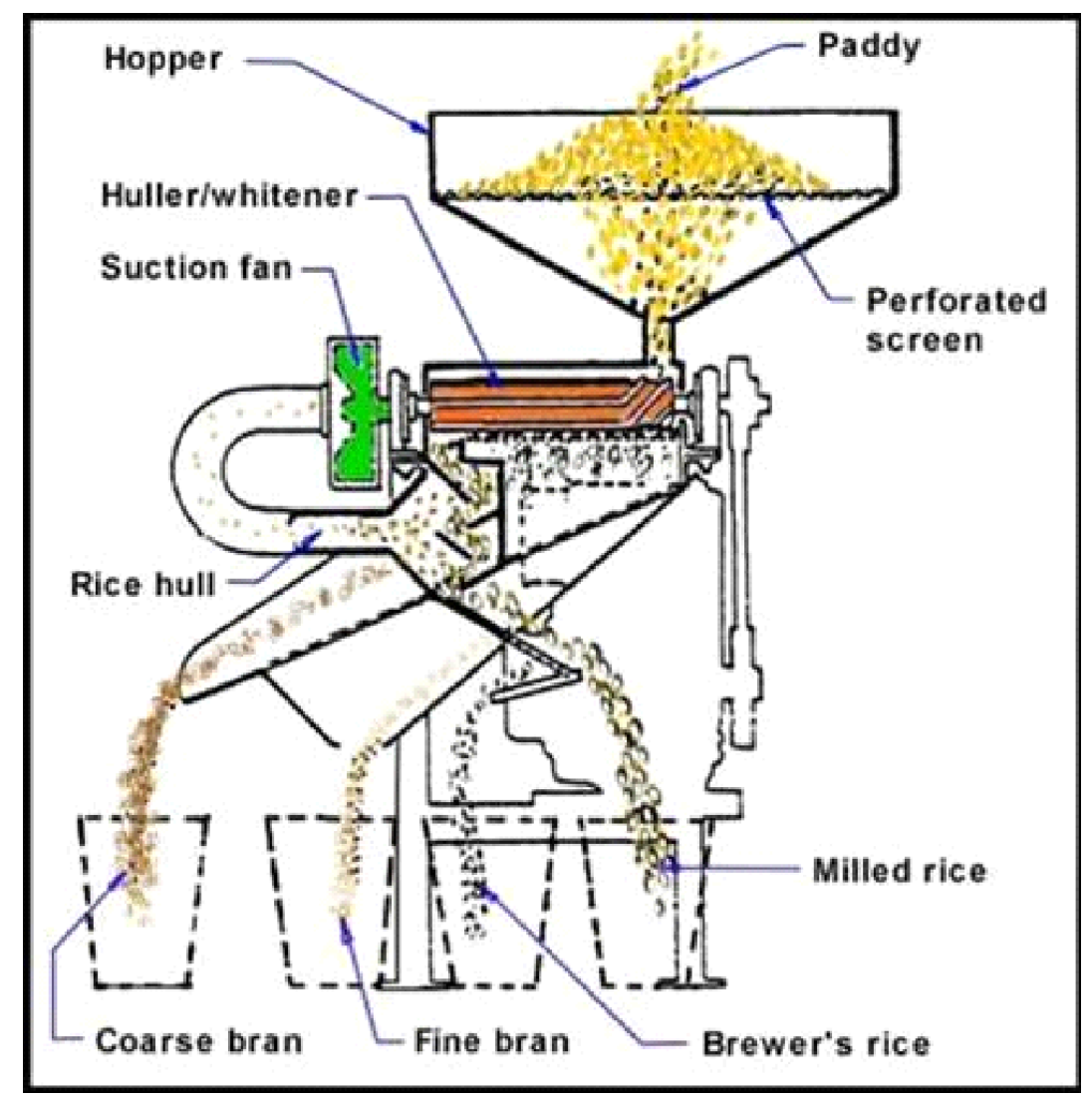

Flow through the IRRI micro mill as an example for a steel husker cum mill.

\section{Performance}

Because of the high breakage, the total milled rice recovery is $53-55 \%$, and head rice recovery is in the order of $30 \%$ of the milled rice.

\section{Advantages}

- Very compact

- $\quad$ Easy to operate.

- Low cost and easy to maintain.

- Can mill small amount of paddy for individual farmers.

- Low cost of milling (handling and conveying equipment is minimal).

\section{Disadvantages}

- Low milling efficiency.

- Produces high amount of cracked and broken rice.

- By-products - husk, bran and very small broken are often mixed

\section{HUSKING WITH RUBBER ROLLS}

The rubber-roller huller is the most efficient hulling machine. As the name suggests two rubber rollers of the same diameter are operated at different speeds to remove the husk from the paddy. One roller has a fixed position and the other is adjustable to meet the desired clearance. The adjustable roller rotates slightly slower 
than the fixed roller. Rubber-roll hullers have an aspirator in the base of the machine to separate the hulls from the brown rice. The roll diameter varies from 150 to $250 \mathrm{~mm}$ and the roller width from 60 to $250 \mathrm{~mm}$. The correct clearance is dependent on the varietal characteristics and the width and length of paddy. This method of hulling can achieve hulling efficiencies of $85 \%$ to $90 \%$ with minimum broken or cracked grain. This type of machine is now widely used in developed countries.

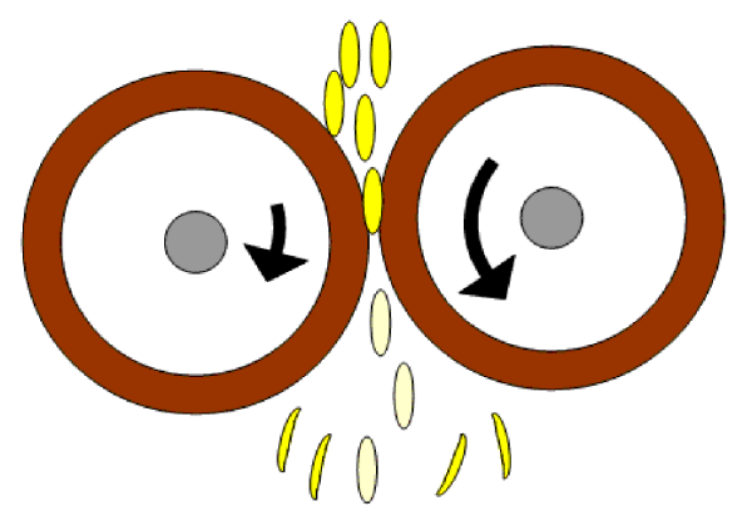

Working principle of a rubber roll husker

\section{SEPARATING THE HUSK FROM THE BROWN RICE}

Rice husk and broken rice are removed from the husked material at the winnowing section which is referred to as aspirator. In the aspirator the material is divided into a mixture of brown rice, unhusked whole grains, and rice husk. The husked material is taken out by suction of the aspirator fan.

After passing through the rubber roll husker, the brown rice and unhusked paddy grain will move the next step: the paddy separator.

Performance: Capacity of the rubber roll husker vary, and depends on the size of the rubber rolls. As an example, a 10-inch wide by 10 -inch diameter roller has a rated milling capacity of 2.5 tons per hour of paddy.

In a properly adjusted rubber roll husker, husking efficiencies can be as high as $95 \%$, however efficiencies are often lower. Besides machine adjustments, uniformity of grain thickness will affect the husking efficiency. If a mixture of varieties is fed into the husker, or paddy grain that did not mature uniformly in the field, husking efficiencies will be lower.

Advantages

- Reduced breakage of milled kernels.

- High hulling efficiency.

- By products are free from sand and silicon.

- Brown rice kernels are not scratched, higher quantity of bran compared to under runner disk husker.

- Machine can incorporate a husk separator.

- Compact in comparison to disc husker.

- Low vibration.

Disadvantages

- Capital cost of machine is very high

- High wear rate of rubber rolls resulting in increases operating costs.

- Higher power consumption compared to disc huller.

- Maintenance cost high - more spares have to replace.

- Requires skilled operator.

- Life of machine is shorter than disc huller and steel huller

\section{DESTONER}

The de-stoner is an important component of the rice mill, particularly when rice is harvested mechanically, or when rough rice is dried on open pavements. The grain gathers a lot of stones and mudball during handling, which must be removed. The de-stoner is a simple vibrating deck and air blower that suspends the grain from the stones. The stones are thrown off in one end and the brown rice in the other end.

\section{1) Rice whitening ${ }^{[8]}$}

White rice is produced from brown rice by removing the bran layer and the germ. The bran layer is removed from the kernel by applying friction to the grain surface either by rubbing the grains against an abrasive surface 
or against each other. The amount of bran removed is normally between $8-10 \%$ of the total paddy weight but this will vary according to the variety and degree of whiteness required.

The process used to whiten brown rice can be classified as either abrasive or friction.

11.1)Abrasive whitening:In this process the grain is whitened by the abrasive action of the rice kernel passing between a moving abrasive surface and stationary screen. The hard rough surface is usually stone or a carborundum type material. The abrasive process peels off the bran layers from the brown rice and applies less pressure on the grain than a friction process and is therefore better suited for long grain varieties. Abrasive polishers can be either vertical or horizontal in design. The vertical cone whitener is very common in many Asian countries.

11.2) Friction whitening: In the friction whitener the grain kernels are forced against each other and a metal screen by a steel-ribbed cylinder rotating inside a metal-plated cylinder. The frictional forces created between individual rice grains and between the grains and the metal screen surface remove the bran layer from the grain. Friction polishers are always horizontal in design and apply more pressure on the grain than an abrasive whitener.

\section{3)Combining whiteners and polishers in the milling line}

The whitening process applies pressure to the grain, which generates heat and causes cracking and breakage of some kernels. To reduce the number of broken grains and the grain temperature during the whitening process, rice is normally passed through two to four whitening and polishing machines connected in series. Rice temperatures should not exceed $43-44^{\circ} \mathrm{C}$ during any process. The arrangement of machines to process the rice during rice whitening is dependent on the physical characteristics rice grains. Proper sequencing of the machines will help reduce the amount of broken kernels during whitening and polishing. The normal arrangement of whitening and polishing long and short grain rice is as follows.

Short grain: Abrasive - Friction - Friction - Polishing

Long grain: Abrasive - Abrasive - Polishing

For mills that produce premium or export quality rice, a mist polisher is employed to brush off remaining bran dust and to create a characteristic gloss on the milled rice.

\section{4)Removal of bran}

In both the abrasive and friction whitener, provisions are made for a jet stream of air through the cylinder and portholes to cool the grain, and blow off fine bran. This minimizes breakage and improves efficiency of subsequent steps in the milling process.

\section{5) Adjusting pressure in whiteners and polishers}

Adjustment of the pressure in whiteners and polishers is crucial in meeting the objectives of milling. A certain pressure is required to peel off the bran: if the pressure is too low, only energy is converted into heat but no bran is removed. Conversely, too much pressure results in generation of broken rice. Pressure adjustment is often based on a judgment call of the operator. Many advanced models however contain an ampere meter (that shows the electric load on the motor drive) that indicates the pressure inside the mill. In friction-type whiteners, pressure is regulated by changing the flow rate of grain through the mill. Flow Rate is adjusted by a weight that puts pressure against the output valve.

\section{2)Grading and blending:-[9][10]}

As countries reach self-sufficiency in rice production, the demand by the consumer for better quality rice has increased. Quality of rice is not always easy to define as it depends on the consumer and the intended end use for the grain. Grain quality is not just dependent on the variety of rice, but quality also depends on the crop production environment, harvesting, processing and milling systems.

The last major step in the modern milling process is the removal of the brokens from the milled rice. Sifters or screen separators are used to separate small brokens, also referred to as brewers rice, from whole grain and large brokens. Sifting will also remove germs and bran still present in the milled rice after whitening and polishing. The large brokens and whole grain are either bagged for delivery to the customer, or further processed through length graders.

For millers catering to the high-end or export market, length graders and blending stations are used. Length grading separates "head rice" from large brokens. Blending stations allow for mixing of head rice and brokens in the correct proportion, as specified by the grade standards. For instance, premium grade rice in the Philippines allows for $95 \%$ head rice and 5\% brokens. 
In most rice-growing countries, milled rice is marketed in bags, and therefore bagging stations from an integral part of the modern rice mill. The size of the bags depend on the requirements of the customer. In larger rice mills that cater to supermarkets, milled rice is packaged in plastic bags of 2,5,10 and 20kg, and packaging is fully mechanized.

\section{1) Characteristics Considered for Grading of Milled Rice}

- Dead rice, brokens and brewers percentages

- Defectives

- Foreign matter

- Presence of paddy

- Whiteness

- Chalkiness

- Moisture content

12.2) Objectives of establishing standards and grades

- To ensure only edible rice reaches the consumer.

- To improve post harvest practices so as to eliminate or reduce waste.

- To improve agronomic practices to increase farm yields.

- To improve processing practices for better milling recoveries and for market expansion.

- To protect consumers from price/quality manipulation.

\section{3) Grades of Indian Rice}

- Common variety: Short bold \& long bold rice

- Fine variety: Medium slender rice

- Superfine variety: Long slender \& short slender rice

\section{4)Length graders: ${ }^{[11]}$}

The common length grader used in modern rice mills is the indented cylinder, also referred to as trieur. It consists of a rotating cylinder with cavities (i.e. indents) inside and a catch trough with a screw conveyor. As the indented cylinder rotates, grains are caught in the indents and lifted. Head rice falls on while broken grains are elevated to the catch trough. The screw conveyor along the axis will convey the brokens outside the cylinder. The entire cylinder is set at a slight angle. Length graders are usually used in series, with indents of various sizes used for each grading step.

\section{3) Sifters:-}

Sifters or screen separators are used to separate small brokens, also referred to as brewers rice, from whole grain and large brokens. Sifting will also remove germs and bran still present in the milled rice after whitening and polishing.

\section{4)Blending station:-}

Blending stations allow for mixing of head rice and brokens in the correct proportion, as specified by the grade standards. For instance, premium grade rice in the Philippines allows for $95 \%$ head rice and 5\% brokens.

\section{5) Bagging station}

In most rice-growing countries, milled rice is marketed in bags, and therefore bagging stations from an integral part of the modern rice mill. The size of the bags depend on the requirements of the customer. In larger rice mills that cater to supermarkets, milled rice is packaged in plastic bags of 2, 5, 10 and 20kg, and packaging is fully mechanized.

The basic bagging station consists of a bagging bin, a platform scale, and a bag closing-sewing machine.

16) Improve the output of rice mill:-

Provided that the quality of paddy received at the rice mill is good, the best quality milled rice will be attained from a mill if a number of guidelines are followed.

\section{Related to raw material}

- $\quad$ Mill at the right moisture content

- $\quad$ Pre-clean paddy before husking

- Do not mix varieties prior to milling

2. Technology

- Use rubber roll technology for husking

- Use a paddy separator

- $\quad$ Consider two-stage whitening 
- $\quad$ Grade the milled rice

3. Management

- $\quad$ Monitor and replace spare parts regularly

\section{REFERENCES}

[1] http://www.rice-trade.com/milling.html

[2] b/index.php/rice-millingwww.knowledgebank.irri.org/rk

[3] b/index.php/rice-millingwww.knowledgebank.irri.org/rk

[4] http://www.knowledgebank.irri.org/rkb/index.php/rice-milling/commercial-rice-milling-systems/husking

[5] http://www.knowledgebank.irri.org/rkb/index.php/rice-milling/commercial-rice-milling-systems/paddypre-cleaner

[6] http://www.knowledgebank.irri.org/rkb/index.php/rice-milling/commercial-rice-millingsystems/husking/steel-husker

[7] http://www.knowledgebank.irri.org/rkb/index.php/rice-milling/commercial-rice-millingsystems/husking/rubber-roll-husker

[8] http://www.knowledgebank.irri.org/rkb/index.php/rice-milling/commercial-rice-milling-systems/ricemilling

[9] http://www.knowledgebank.irri.org/rkb/index.php/rice-milling/commercial-rice-milling-systems/gradingand-blending

[10] http://www.rice-trade.com/quality-grading.html

[11] Internationall rice research institute copyright papers

[12] http://mofpi.nic.in/EDII_AHMD/Cereal_Pulse/14\%20Rice\%20mill.pdf 